\title{
A synchronous occurrence of bifocal intracranial germinoma and bilateral testicular epidermoid cyst in an adolescent patient with Klinefelter's syndrome
}

\author{
Derya Özyörük ${ }^{1}$, Ayça Kocayozgat ${ }^{1}$, İnci Yaman-Bajin $^{1}$, Faik Çetindă̆², \\ Ayşe Selcen Oğuz-Erdoğan³ ${ }^{3}$ Altan Güneş ${ }^{4}$ \\ Divisions of ${ }^{1}$ Pediatric Oncology, ${ }^{3}$ Pathology and ${ }^{4}$ Radiology, Ankara Children's Hematology and Oncology Education and \\ Research Hospital; ${ }^{2}$ Division of Radiation Oncology, Abdurrahman Yurtaslan Oncology Education and Research Hospital, \\ Ankara, Turkey.E-mail: dozyoruk@yahoo.com
}

Received: 9th January 2019, Revised: 18th February 2019, Accepted: 4th March 2019

\begin{abstract}
SUMMARY: Özyörük D, Kocayozgat A, Yaman-Bajin İ, Çetindağ F, OğuzErdoğan AS, Güneş A. A synchronous occurrence of bifocal intracranial germinoma and bilateral testicular epidermoid cyst in an adolescent patient with Klinefelter's syndrome. Turk J Pediatr 2019; 61: 456-459.

Klinefelter syndrome (KS) is characterized by an additional X chromosome in males leading to a karyotype of $47, \mathrm{XXY}$. It is associated with an increased risk of certain malignancies, including leukemia, breast cancer and extragonadal germ cell tumor such as mediastinal germ cell tumors and rarely intracranial germ cell tumors. It is possible that the increased risk of developing certain cancers can be attributed to a direct effect of the chromosomal abnormality or the combined action of the abnormal chromosomes and hormonal imbalances. Here we describe a synchronous occurrence of bifocal intracranial germinoma and bilateral testicular epidermoid cyst in an adolescent patient with Klinefelter's syndrome. The synchronous occurrence of the dual tumors in this patient with Klinefelter's syndrome might be resulted from the migration defect during embriyogenesis due to underlying genetic disease or it is a coincidental condition, yet there has been no case reported in the literature, so far.
\end{abstract}

Key words: Klinefelter's syndrome, germinoma, bilateral testicular epidermoid cyst.

In children, central nervous system (CNS) germ cell tumors (GCTs) represent approximately $3 \%$ of primary pediatric brain tumors and encompass a wide pathologic spectrum. They are most commonly located in the pineal and suprasellar regions of the brain and can be divided into major groups including germinomas and nongerminomatous GCTs (NGGCTs). ${ }^{1-3}$ Epidermoid cyst of the testis is very rare in childhood and account for approximately $1 \%$ of all testicular tumors. According, to a widely accepted theory, it represents monodermal or unilateral development of a teratoma., ${ }^{4,5}$ Shah et al. ${ }^{4}$ suggested that the epidermoid cyst is a subtype in the category of germ cell tumors of the testis. Here we describe a syncronous occurance of bifocal intracranial germinoma and bilateral testicular epidermoid cyst in an adolescent patient with Klinefelter's syndrome.

\section{Case Report}

A 17-year-old boy was admitted to our clinic after the resection of a pineal mass and diagnosed with germinoma. On his past history, he had febrile convulsion at 2 years of age. The family history was unremarkable except his grandfather who had been diagnosed with colorectal cancer and prostate cancer. The physical examination revealed atypical face, low-set ears, longer arms and legs, right scrotal mass with diameters of $1.5 \times 1.5 \mathrm{~cm}$. Laboratory tests were within normal limits. The serum and cerebrospinal fluid alpha-fetoprotein (AFP) and human 
chorionic gonadotropin beta-subunit levels $(\beta-h C G)$ were also within normal limits. The plasma luteinizing hormone and folliclestimulating hormone levels were $11.5 \mathrm{mIU} /$ $\mathrm{mL}$ and $8.8 \mathrm{mIU} / \mathrm{mL}$, respectively. The plasma testosterone was low $(1.93 \mathrm{ng} / \mathrm{mL})$. The levels of other anterior pituitary hormones were normal. The visual field test was normal. The pre-operative magnetic resonance imaging (MRI) of the brain showed a mass in the pineal region with $29 \times 25 \mathrm{~mm}$ diameters and thickened pituitary stalk measuring $7 \times 6 \mathrm{~mm}$ with nodular enhancement together with significant post-contrast enhancement in tuber cinerium associated with rathke cleft cyst (Fig. $1 \mathrm{~A})$. After three weeks of near total excision of pineal mass, post-operative MRI showed no residue in pineal region but other lesions were remained the same (Fig. 1,B). The spinal MRI showed no metastases. The cerebrospinal fluid (CSF) cytology was found normal. The paraffin blocks were re-evaluated and histopatologic investigation revealed pure germinoma (Fig. 2 A,B). A computed tomography (CT) scan of the chest and abdomen were found to be normal. An ultrasound examination of scrotum demonstrated bilateral heterogeneous avascular testicular masses. The right testicular mass measured as $1.6 \mathrm{~cm} \times 1.1 \mathrm{~cm}$ and demonstrated a somewhat concentric, lamellated appearance with alternate hypoechoic and echogenic layers. The left testicular mass was hypodense and measured $1.1 \mathrm{~cm}$ in diameter. MRI of bilateral testicular lesions showed nodular pattern with lowsignal intensity on the T1-weighted image and of high-signal intensity on the T2-weighted image (Fig. 1C). Chromosome analysis revealed a 47 XXY karyotype, and non-mosaic Klinefelter's syndrome was diagnosed. Semen analysis showed azoospermia. Testis-sparing surgery with enucleation of the tumor was performed to preserve fertility and avoid testosterone deficiency, with concomitant

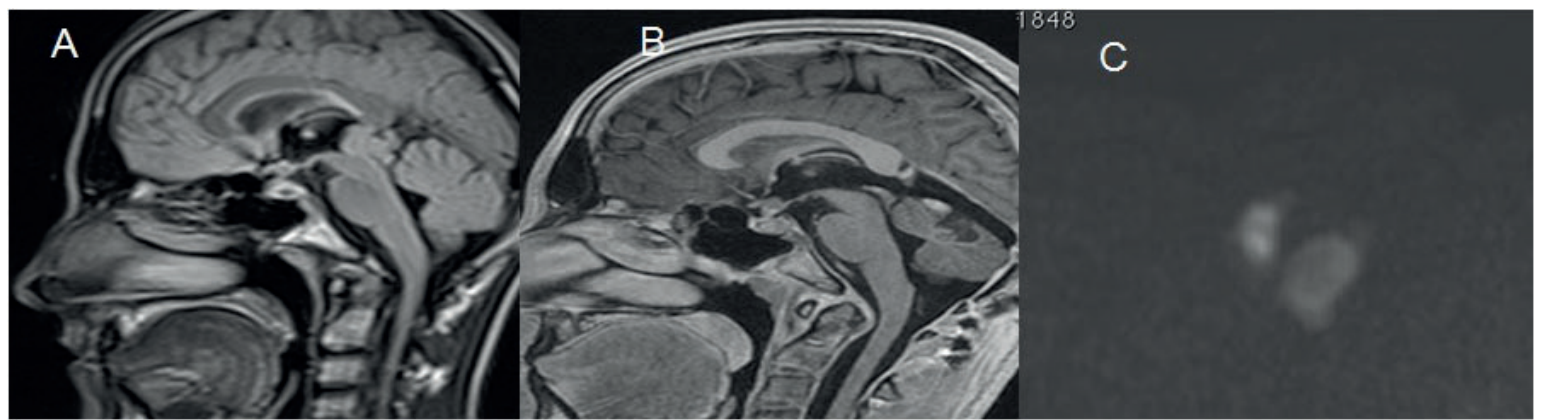

Fig. 1. A. The pre operative magnetic resonance imaging(MRI) of brain showed pineal region mass in 29x25 mm diameters and thickened pituitary stalk measuring 7x6 mm with nodular enhancement together with significant post-contrast enhancement in tuber cinerium associated with rathke cleft cyst. B. The post operative MRI of brain showed no residue in pineal region but the other suprasellar lesion was remained the same. C. MRI of bilateral testicular lesions showed nodular lesions of low-signal intensity on the T1weighted image and of high-signal intensity on the T2-weighted image.

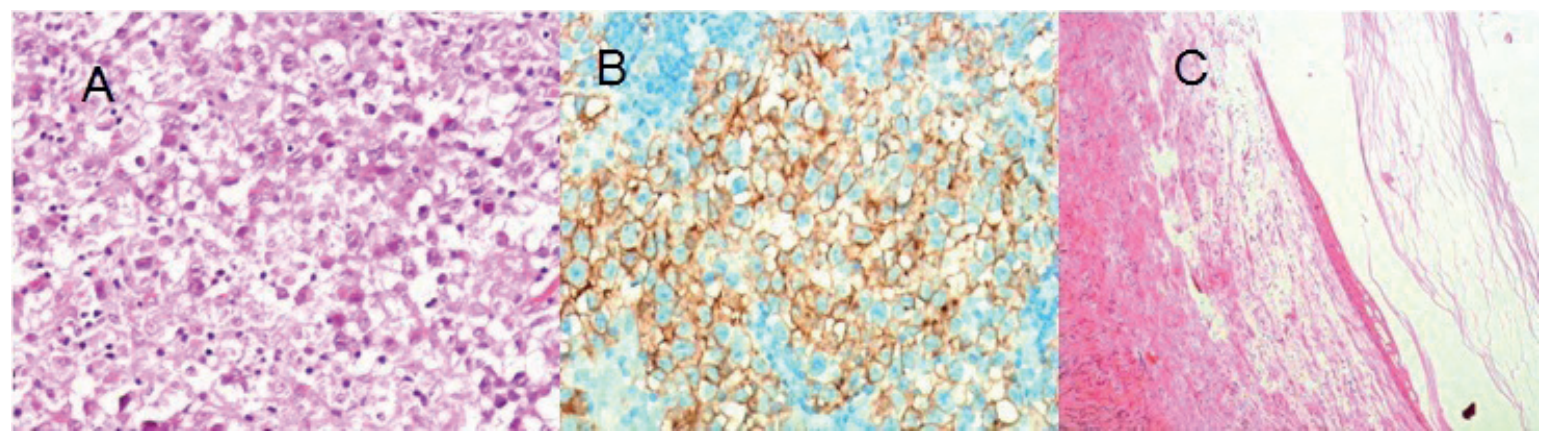

Fig. 2. A. Hematoxylin and eosin stain of tissue $(70 \times$ magnification) obtained from a pineal tumor of a patient presenting with synchronous bifocal masses, whichdisplays a germinoma B. Immunoperoxidase stain for CD 117 and PLAP reveals the positive staining of cells in the germinoma C. The histological examination revealed an epidermoid cyst of the bilateral testis. 
use of intraoperative frozen section histologic analysis, to rule out occult malignancy within the tumor. Also, multiple biopsies were performed to rule out the case of intratubular germ cell neoplasia (ITGCN) presence. The histological examination revealed an epidermoid cyst of the bilateral testis (Fig. 2C). The patient with Klinefelter's syndrome was diagnosed with bifocal intracranial germinoma together with bilateral testicular epidermoid cyst. According to modified Chang staging system, the patient was staged as T1M0. He received 4 cycles of carboplatine and etoposide at 3-week intervals. Each cycle of chemotherapy consisted of carboplatin $300 \mathrm{mg} / \mathrm{m} 2$ on days 1 and 2 along with etoposide $150 \mathrm{mg} / \mathrm{m} 2$ on days 1,2 and 3. After 3-week of chemotherapy, the whole ventricular system with a $0,7-1 \mathrm{~cm}$ margin received 23,4 Gy in 13 fractions of 1,8 Gy followed by sequential boost to the primary tumor with a $1,5 \mathrm{~cm}$ margin of $8 \mathrm{~Gy}$ in 4 fractions of $2 \mathrm{~Gy}$, for a total dose of 31,4 Gy using intensity-modulated radiation therapy (IMRT) beam. ${ }^{2,6} \mathrm{He}$ has been following up on remission for 6 months. Informed consent was received from the family.

\section{Discussion}

It is suggested that the patients presenting with synchronous bifocal intracranial tumors (masses in the pineal and neurohypophyseal region), detectable $\beta$-hCG levels (5-100 mIU/ $\mathrm{mL})$ and normal AFP levels $(</=10 \mathrm{ng} / \mathrm{mL})$ are usually diagnosed with pure germinoma without any pathologic confirmation. ${ }^{1-5}$ On the other hand, Aizer et al. ${ }^{1}$ suggested that clinicians should strongly consider a biopsy in patients presenting with bifocal masses and normal or modestly elevated biomarkers, because misclassification of such cases as germinomas could result in under treatment and a possible increased risk for recurrence according to their study. Our case had been operated when he referred to our pediatric oncology clinic and the histopathologic investigation of resected pineal mass revealed pure germinoma.

Although, craniospinal radiotherapy has traditionally been considered the gold standard treatment for intracranial germinoma, its late neurologic detrimental effects led to physicians omitting spinal irradiation and reducing the radiation field as much as possible in limited disease. ${ }^{7}$ In recent years, it has been reported that patients with localized intracranial germinoma treated with four cycles of carboplatin and etoposide noted an excellent response rate of $95 \%$ with $100 \%$ OS at 3 years following reduced radiotherapy. ${ }^{3}$ Similar to that, our patient has been treated with the same chemotherapy followed by whole ventricular and local boost irradiation.

Klinefelter syndrome is a common genetic disorder characterized by an additional $\mathrm{X}$ chromosome in males leading to a karyotype of $47, \mathrm{XXY}$. The clinical syndrome was first described nearly 75 years ago in several males with small testes, tall stature, gynecomastia, and azoospermia. ${ }^{8-10}$ Klinefelter's syndrome is associated with an increased risk of certain malignancies, including leukemia, breast cancer and extragonadal germ cell tumor such as mediastinal germ cell tumors and rarely intracranial germ cell tumors. It has been suggested that stimulation of gonadotropin and estrogen sensitive tissues might predispose patients with Klinefelter syndrome to the development of malignancies. ${ }^{11-14}$

The first case of Klinefelter's syndrome associated with intracranial germ cell tumor with the high plasma AFP and $\beta$-hCG concentrations of patient were $868 \mathrm{ng} / \mathrm{ml}$ and $68.6 \mathrm{IU} / \mathrm{ml}$ respectively was reported in 1987. He died because of talamic bleeding after radiotherapy. ${ }^{12}$ Prall et al. ${ }^{13}$ reported a case of intracranial mixed malignant germ cell tumor (GCT) together with Klinefelter syndrome in 1995. According to their report, their case represents the sixth reported case of intracranial GCT with Klinefelter syndrome but the first to be histologically confirmed to have mixed malignant germ cell elements in English literature. Therefore, they strongly emphasizesed the need for a histopathological diagnosis prior to initiation of therapy. In addition, Ahagon et al. ${ }^{15}$ reported a Klinefelter syndrome associated with suprasellar germinoma case which is scarcely found in the literature. So far, only one case of bilateral epidermoid testicular cyst associated with Klinefelter's syndrome was reported. ${ }^{16}$ The treatment of testicular epidermoid cysts has varied. The preferable treatment, whether 
radical orchiectomy or testis-sparing surgery, remains controversial. Although, in terms of psychological implications and preservation of fertility, testis-sparing surgery is desirable. ${ }^{4,5,17}$

It is well known that the primordial germ cells appear in the yolk sac wall in the third gestational week and migrate via the dorsal mesentery of the hindgut into the genital ridge at the 6th gestational week. If primordial germ cells are disturbed and some cells stray into other places, extragonadal GCT develops later in retroperitoneum, mediastinum or diencephalons, during the migration. The dual occurrence of 2 primary germ cell tumors in one patient result from a mutation in the germ cell line or oncogenic factors simultaneously affect the gonadal and the extragonadal germ cell. ${ }^{18}$ Unfortunately, we could not explained if the syncronous occurance of a bifocal secretory intracranial germinoma and bilateral testicular epidermoid cyst in our patient with Klinefelter's syndrome was resulted from the migration defect during embriyogenesis due to the underlying genetic disease or only a coincidental condition.

In conclusion, the synchronous occurrence of the dual tumors in this patient with Klinefelter's syndrome might be resulted from the migration defect during embriyogenesis due to the underlying genetic disease or maybe a coincidental condition, yet there has been no case reported in the literature, so far.

\section{REFERENCES}

1. Aizer AA, Sethi RV, Hedley-Whyte ET, et al. Bifocal intracranial tumors of nongerminomatous germ cell etiology: Diagnostic and therapeutic implications. Neuro Oncol 2013; 15: 955-960.

2. Calaminus G, Kortmann R, Worch J, et al. SIOP CNS GCT 96: Final report of outcome of a prospective, multinational nonrandomized trial for children and adults with intracranial germinoma, comparing craniospinal irradiation alone with chemotherapy followed by focal primary site irradiation for patients with localized disease. Neuro Oncol 2013; 15: 788796.

3. Khatua S, Dhall G, O'Neil S, et al. Treatment of primary CNS germinomatous germ cell tumors with chemotherapy prior to reduced dose whole ventricular and local boost irradiation. Pediatr Blood Cancer 2010; 55: 42-46.
4. Shah KH, Maxted WC, Chun B. Epidermoid cysts of the testis: A report of three cases and an analysis of 141 cases from the world literature. Cancer 1981; 47: 577-582.

5. Yoshida T, Takao T, Tsujimura A, Tomita H, Aozasa $\mathrm{K}$, Okuyama A. Testicular epidermoid cyst in Klinefelter's syndrome. Int J Urol 2006; 13: 478-480.

6. Calaminus G, Frappaz D, Kortmann RD, et al Outcome of patients with intracranial nongerminomatous germ cell tumors-lessons from the SIOP-CNS-GCT-96 trial. Neuro Oncol 2017; 19: 1661-1672.

7. Aoyama H, Shirato H, Kakuto Y, et al. Pathologicallyproven intracranial germinoma treated with radiation therapy. Radiother Oncol 1998; 47: 201-205.

8. Davis S, Howell S, Wilson R, et al. Advances in the Interdisciplinary Care of Children with Klinefelter syndrome. Adv Pediatr 2016; 63: 15-46.

9. Queipo G, Aguirre D, Nieto K, et al. Intracranial germ cell tumors: Association with Klinefelter syndrome and sex chromosome aneuploidies. Cytogenet Genome Res 2008; 121: 211-214.

10. Schneider DT, Calaminus G, Koch S, et al Epidemiologic analysis of 1,442 children and adolescents registered in the German germ cell tumor protocols. Pediatr Blood Cancer 2004; 42: 169-175.

11. Lynch HT, Kaplan AR, Lynch JF. Klinefelter syndrome and cancer. A family study. JAMA 1974; 229: 809-811.

12. Oki S, Nakao K, Kuno S, Imura H. A case of Klinefelter's syndrome associated with hypothalamicpituitary dysfunction caused by an intracranial germ cell tumor. Endocrinol Jpn 1987; 34: 145-151.

13. Prall JA, McGavran L, Greffe BS, Partington MD. Intracranial malignant germ cell tumor and the Klinefelter syndrome. Case report and review of the literature. Pediatr Neurosurg 1995; 23: 219-224.

14. Swerdlow AJ, Schoemaker MJ, Higgins CD, Wright AF, Jacobs PA; UK Clinical Cytogenetics Group. Cancer incidence and mortality in men with Klinefelter syndrome: A cohort study. J Nat Cancer Inst 2005; 97: 1204-1210.

15. Ahagon A, Yoshida Y, Kusuno K, Uno T. Suprasellar germinoma in association with Klinefelter's syndrome. Case report. J Neurosurg 1983; 58: 136138.

16. Alapont Alacreu JM, Dominguez Hinarejos C, Serrano Durba A, et al. Bilateral testicular epidermoid cyst in a pediatric patient with Klinefelter syndrome. Actas Urol Esp 2003; 27: 742-744.

17. Sasagawa I, Nakada T, Kazama T, Sakamoto M, Satomi S, Katayama T. Epidermoid cyst of the testis in Klinefelter's syndrome. Urol Int 1987; 42: 398-400.

18. Trentini GP, Maiorana A, De Benedittis A. Metachronous seminoma of the pineal region and right testis. Case report. Appl Pathol 1985; 3: 129133. 